\title{
Evaluation of Time Diversity Technique for Satellite Mitigation in Tropical Climate
}

\author{
M. M. Yunus ${ }^{1}$, N. Samin ${ }^{1}$, J. Din ${ }^{2}$, S. L. Jong ${ }^{3}$ \\ ${ }^{1}$ Centre of Telecommunication Research and Innovation (CeTRI), Faculty of Electronic and Computer Engineering, \\ Universiti Teknikal Malaysia Melaka, Hang Tuah Jaya, 76100 Durian Tunggal, Melaka, Malaysia \\ ${ }^{2}$ Wireless Communication Centre (WCC), Faculty of Electrical Engineering, Universiti Teknologi Malaysia, 81200 \\ Skudai, Johor, Malaysia \\ ${ }^{3}$ Faculty of Electrical and Electronic Engineering, Universiti Tun Hussein Onn Malaysia, 86400 Batu Pahat, Johor, \\ Malaysia
}

\begin{tabular}{l} 
Article Info \\
\hline Article historys: \\
Received Oct 14, 2020 \\
Revised May 26, 2021 \\
Accepted Jun 24, 2021 \\
\hline
\end{tabular}

\section{Keywords:}

Time diversity

Fade mitigation

Propagation impairment

Rain attenuation

Satellite

\begin{abstract}
Time diversity is one of the mitigation techniques for satellite communications (SatCom) systems that aims to combat deep fades cause by propagation impairments. This study presents the performance of time diversity technique for rain attenuation at $\mathrm{Ku}-$ and $\mathrm{Ka}-$ band SatCom systems in Johor Bahru, Malaysia. The Synthetic-Storm Technique (SST) has been utilized to obtain rain attenuation time series based on rain rate data measured by local rain gauge. The time diversity has been quantified through diversity gain as a function of retransmission time delay, in which shows the effectiveness of time diversity technique to improve the Quality of Service (QoS) and link availability. The results demonstrated it is feasible to use time diversity as mitigation technique at higher frequencies in a mission to support future SatCom operation in tropical region.
\end{abstract}

Copyright () 2019 Institute of Advanced Engineering and Science. All rights reserved.

\section{Corresponding Author:}

Mawarni binti Mohamed Yunus,

Centre of Telecommunication Research and Innovation (CeTRI),

Faculty of Electronic and Computer Engineering,

Universiti Teknikal Malaysia Melaka,

Hang Tuah Jaya, 76100 Durian Tunggal, Melaka, Malaysia.

Email: mawar@utem.edu.my

\section{INTRODUCTION}

Growing demand on high data rate to keep up with advanced multimedia services has led to the usage of higher frequency bands (Ku-band and above) in satellite communication systems. Such frequencies enable larger amount of bandwidth to support higher transmission rate thus opening the door to faster and efficient communication to the users [1]. However, at these frequency bands, propagation impairments are very prominent particularly in tropical climate due to heavy precipitation. In this respect, the concept of adaptive Fade Mitigation Techniques (FMTs) must be adopted to minimize signal degradation and provide reliable Earth-space link availability [1][2].

There are two categories of FMT; which are compensation and avoidance type [2]. Compensation FMT works by modifying the link resources and signal parameters to improve the quality of the received signal, whereas avoidance type of FMT works by re-routing the link onto less impaired signal called as diversity. Correspondingly, avoidance type FMT are preferable in terms of simplicity and effectiveness in compensating fades [2]. The most common technique for avoidance type FMT is site diversity, which attempts to compensate the fades by re-routing the path link by taking advantage of finite size of rain cell. However, site diversity is more expensive option to implement as the need of two inter-connected earth station [3]. Another recent 
technique which has attracted the researcher's attention is time diversity.

Time diversity counteract the channel fading by retransmitting the same information at suitable time delays, so that the impairments may be avoided [3], [4]. One of the main advantages of the implementation of this technique is that no additional network equipment is required. Although limited to non-real-time applications, time diversity seems to provide viable choice as current satellite services demands variety of different information that does not require real-time communications [3]. The evaluation of time diversity performance to overcome rain attenuation has been done in the past using several different approaches including direct experimental measurements [4], [5] and modeling approaches [6] - [9]. Nevertheless, most of the studies have been carried out in the temperate countries, which exhibit lower yearly rain rate than in tropical, whereas studies in heavy rain region mostly concentrated at Ku-band frequency only [10] - [12]. Alternative methods are needed as reliable experimental data particularly at higher frequencies are not available at most of the places. An effort to model time diversity technique utilizing 1-minute rain rate data has been made in [13]. The work assumed that rain rate with delay function may represent rain attenuation with delay for the same time and location. However, the study limited only at $12 \mathrm{GHz}$ band, and no further studies has yet been made for higher frequencies. Rain dissipates higher energy at these range which leads to more serious link outage during heavy downpour [14]. Therefore, it is worthwile to further investigate the performance of time diversity technique for future Satcom operations at Ka-band.

In the case of lack rain attenuation experimental data, Synthetic-Storm Technique (SST) can be performed to generate rain attenuation time series based on local rain rate data measured. SST model whose theory has been developed by Matriciaani [15] has been proven to provide rain attenuation statistics that matches well with the measurements including in tropical region [11], [16], thus expected to provide valid approach in analyzing time diversity performance. This contribution presents an analysis performance of time diversity technique in tropical climate by using SST model extended to $\mathrm{Ku}$ - and $\mathrm{Ka}$-band frequencies. A brief description of time diversity technique and SST model are first given in Section 2, as well as the measurement and input parameters. Then, probability distribution of rain attenuation for $\mathrm{Ku}$ - and $\mathrm{Ka}$-band are presented and compared to ITU-R prediction [17] in Section 3. The analysis is then continued with the probability of attenuation when time diversity is implemented, as well as the assessment of diversity gain in terms of time delays.

\section{SYSTEM MODEL}

\subsection{Time Diversity Technique}

The basic idea of time diversity is repetition or duplication of information. The same stream of information is transmitted twice with the second transmission is delayed at $\Delta t$. As illustrated in Figure 1, the satellite transmits a stream of information ' $a$ ' to the receiver (ground station) during rain event, after delaying at $\Delta \mathrm{t}$, the same information is sending again in a new stream, ' $\mathrm{b}$ '. The receiver will then select the clearest information that provide lower attenuation value [12].

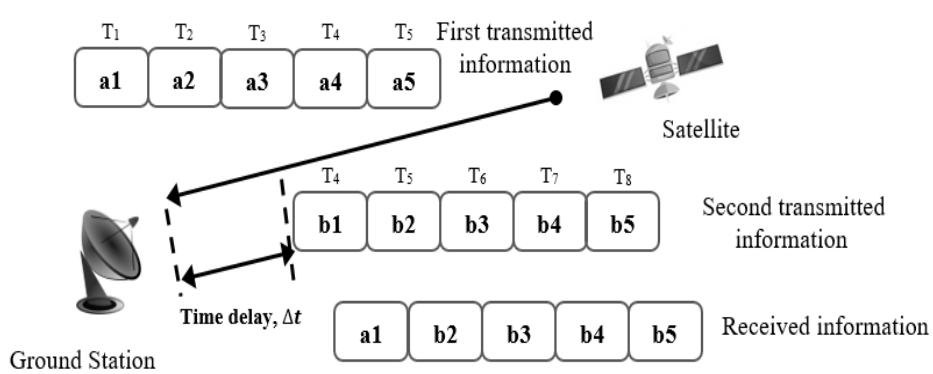

(a)

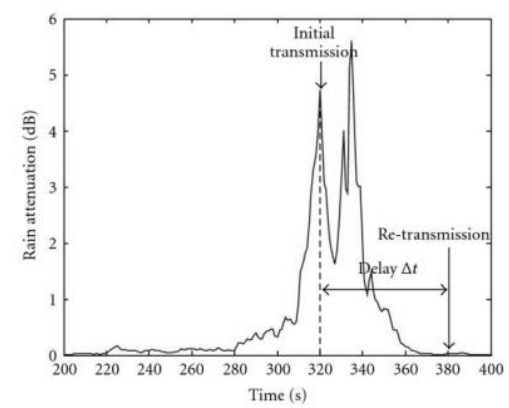

(b)

Figure 1. Illustration of time diversity scheme in satellite link [8], [12]

The primary factor to demonstrate the performance of time diversity is diversity gain, $G(t)$, which is the value of the difference in $\mathrm{dB}$ between the rain attenuation of the original received signal and the signal with $\Delta t$. Correspondingly, the time diversity gain can be defined as follows, 


$$
G_{\Delta t}(t)=A(t)-A(t+\Delta t)
$$

where $A(t)$ is the original attenuation without time delay and $A(t+\Delta t)$ is the attenuation with time delay of $\Delta t$. Notice in Figure 1(b) that the original attenuation is always $A(t)>0$ whereas values of $A(t+\Delta t)$ can be equal to zero indicates that the rain is over when the retransmition occurs [4]. Another useful parameter to quantify the performance of time diversity technique is relative diversity gain, $g(t)$, calculated by

$$
g(t)=\frac{G_{\Delta t}(t)}{A(t)} \cdot 100[\%]
$$

One of the key motivations to utilize time diversity is the fact that most of the rain events have limited duration. Taking advantage of the fast temporal of the rain process, time diversity allows the reduction of fade margin for a given availability, thus enhances the signal performance.

\subsection{Synthetic-Storm Technique (SST) and Input Parameters}

SST is well-known reliable physical mathematical model that transforms time series of rain rate, which is measured by using a rain gauge at a point for 1-minute, to a rain attenuation time series along the path, using an estimation of the storm translation speed, from time to distance [15]. To complete this process, several information is required such as the length of the signal path through the rain cell, the rain cell velocity, and the rain rate at the site under experiment. The calculation of SST rain attenuation over a satellite path follows the basic assumption shown in Figure 2.

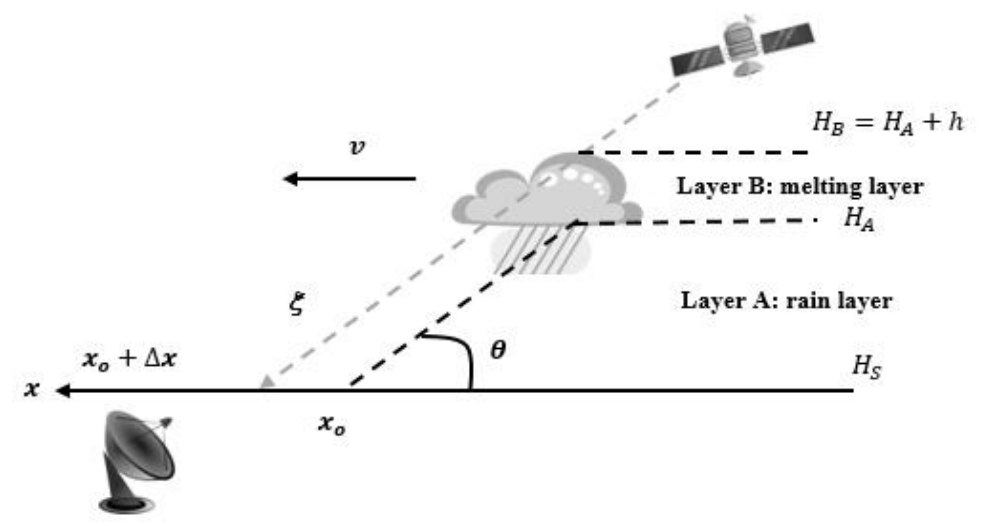

Figure 2. Vertical structure of precipitation and geometrical parameters [15]

Troposphere's vertical structure in SST is assume at two layers: consisting of rain layer A and melting layer B. Equation below is a signal attenuation of satellite path that has been acquired from specific attenuation at a certain point.

$$
A\left(x_{o}\right)=k_{A} \int_{0}^{F_{A}} R^{\alpha_{A}}\left(x_{o}+\Delta x_{o}, \xi\right) \mathrm{d} \xi+k_{B} r^{\alpha_{B}} \int_{L_{A}}^{F_{B}} R^{\alpha_{B}}\left(x_{o}, \xi\right) \mathrm{d} \xi
$$

$A(x)$ is the attenuation at a particular point and $\xi$ is the distance measured along the satellite path. $k$ and $\alpha$ are the regression coefficients of specific attenuation, which computed at $20^{\circ} \mathrm{C}$ and $0^{\circ} \mathrm{C}$ for layer $\mathrm{A}$ and $\mathrm{B}$, respectively. The constants for $\mathrm{Ku}$ - and Ka-band are taken from [18] as an input. The "apparent" rain rate $\left(R_{B}\right)$ in Layer B is assumed to be uniform and given by 3.134 times greater than the ground rain rate $\left(R_{A}\right)$. Then, the radio path lengths $L_{A}$ and $L_{B}$ are calculated using,

$$
\begin{aligned}
L_{A} & =\left(\frac{H_{A}-H_{S}}{\sin \theta}\right) \\
L_{B} & =\left(\frac{H_{B}-H_{S}}{\sin \theta}\right)
\end{aligned}
$$


The height above mean sea level of the precipitation (rain layer and melting layer) is described at specified latitudes and can be expressed as:

$$
\begin{array}{ll}
H_{B}=5 & \phi<23^{\circ} \\
H_{B}=5-0.075(\phi-23) & \phi \geq 23^{\circ}
\end{array}
$$

According to [19], depth of the melting layer, $h$ is assumed to be $400 \mathrm{~m}$ regardless of the latitude. Thus, the effective height of the rain is provided by,

$$
H_{A}(\phi)=H_{B}(\phi)-h
$$

with $H_{B}$ given by (6). From the simulation, the effective rain height is $4.97 \mathrm{~km}$ at Johor Bahru. $H_{S}$ is the ground station height above mean sea level and $\theta$ is the elevation angle of the slant path. Further parameters are given as,

$$
x_{o}=\Delta L \cos \theta=\frac{h}{\tan \theta}
$$

where,

$$
\Delta L=L_{B}-L_{A}=\frac{h}{\sin \theta}
$$

$\Delta x$ is the shift that account the path enters layer A at location of $x_{o}+\Delta x$, as in the first term of right-hand side of equation (3). The other input parameters used to perform SST for required $\mathrm{Ku}$ - and $\mathrm{Ka}$-band systems in Johor Bahru are listed in Table 1.

Table 1. Synthetic Storm Technique Prediction Model Input parameters

\begin{tabular}{cc}
\hline Input Parameters & Values \\
\hline One-minute rain rate & $\mathrm{R}_{1}$ \\
Latitude/Longitude & $1.5585^{\circ} \mathrm{N} / 103.6382^{\circ} \mathrm{E}$ \\
Frequency & $12 \mathrm{GHz}$ (Ku-Band)/ \\
& $20 \mathrm{GHz}$ (Ka-Band) $/$ \\
Polarization Angle & $90^{\circ}$ (Linear) \\
Elevation Angle & $75.6^{\circ}$ (Geostationery of Measat-3 Broadcast \\
Storm Velocity & Satlite at $91.5^{\circ} \mathrm{E}$ is assumed) \\
& $6.24 \mathrm{~m} / \mathrm{s}$ (local wind speed at 700 mbar pressure \\
level) \\
Height above mean sea level & $50 \mathrm{~m}$ \\
\hline
\end{tabular}

\section{RESULTS AND DISCUSSION}

In satellite communication link design, rain attenuation statistics is prominent parameter for system designer to realistically determine link reliability. Thus, CCDFs of $\mathrm{Ku}(12 \mathrm{GHz})$ and $\mathrm{Ka}-\mathrm{band}(20 \mathrm{GHz})$ of one-year duration statistically derived from SST in Johor Bahru are shown in Figure 3. For Ku-band, the SST rain attenuation with outage time of $0.1 \%$ (corresponding to $99.9 \%$ availability), is about $9 \mathrm{~dB}$ and for $0.01 \%$ of the outage time (corresponding to $99.99 \%$ availability) is $18 \mathrm{~dB}$. Meanwhile, for Ka band, the SST rain attenuation at $0.1 \%$ of the outage time required fade margin of $17.5 \mathrm{~dB}$ and for $0.01 \%$ of the time approximated $54 \mathrm{~dB}$ fade margin is required. These values signified quite high values of attenuation especially in tropical region which also indicates that higher frequency such as $\mathrm{Ka}$ band $(20 \mathrm{GHz})$ is more susceptible to attenuation compared to Ku band (12 GHz).

Despite that, rain attenuation statistics predicted by ITU-R [17] and SST is also compared in Table 2 for outage time of $0.1 \%$ and $0.01 \%$. The results are in well agreement for $0.1 \%$ of time and but overestimates at high percentage of time. The differences need to be further validated with experimental results. The results also indicate requirement fade margin for corresponding link availability for both $\mathrm{Ku}$ and Ka-band frequency in Johor Bahru. System that built with these values will ensuring the reliability and guarantee customer satisfaction. 


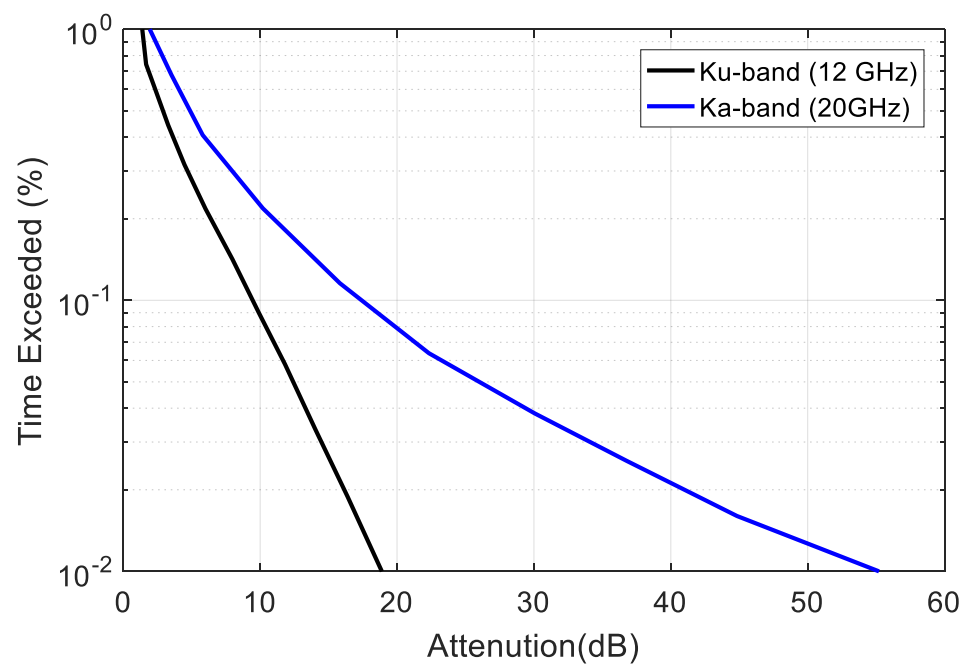

Figure 3. CCDFs of SST Rain Attenuation for Ku and Ka-band in Johor Bahru

Table 2. Summarization of analysis on CCDF of rain attenuation prediction

\begin{tabular}{ccc|cc}
\hline \% link & \multicolumn{3}{c}{ Required Fade Margin } \\
\cline { 2 - 5 } availability & \multicolumn{3}{c}{ Ku-band } & Ka-band \\
\cline { 2 - 5 } & SST & ITU-R & 17.5 & ITU-R \\
$99.9 \%$ & 9 & 8 & 54 & 18 \\
$99.99 \%$ & 18 & 15 & 40.5 \\
\hline
\end{tabular}

In this work, time diversity has been analyzed based on several time delays $(1,5,10,20$ and 30 minutes) as displays in Figure 4 and 5 for $\mathrm{Ku}$ and $\mathrm{Ka}$ band, respectively. $\mathrm{T}_{\mathrm{d}}=0$ indicates to no time diversity being implement which correspond to zero-time delay. Comparison has been made for conventional system that does not apply time diversity $\left(\mathrm{T}_{\mathrm{d}}=0\right)$ with system that implement the diversity. Based on the comparison, the advantage of using time diversity is apparent where it is proved that the attenuation level exceeding a given percentage of time shows significant decrease as the time delay increases. For example, for Ku band at $0.01 \%$ of probability without implementing time diversity, $\mathrm{T}_{\mathrm{d}}=0$, the rain attenuation is $18 \mathrm{~dB}$. After the time delays being used, the attenuation level has decreased to $17.1,15,12,8.5$ and 7.2 correspond with time intervals of 1 , $5,10,20$ and 30 minutes. This result also indicates that for 10 minutes' outage tolerance has significantly lowered the fade margin requirement nearly to $6 \mathrm{~dB}$ for $99.99 \%$ of link availability in this region.

As for the $\mathrm{Ka}$ band at $0.01 \%$ of probability without implementing time diversity, $\mathrm{T}_{\mathrm{d}}=0$, the rain attenuation is $54 \mathrm{~dB}$. After the time delays being used, the attenuation level has decreased to 52, 44, $38.2,31$ and $28.5 \mathrm{~dB}$ correspond with time gaps of $1,5,10,20$ and 30 minutes. This result depicts that for 10 minutes' outage tolerance has reduced the fade margin requirement to $15 \mathrm{~dB}$ for $99.99 \%$ of link availability in this region.

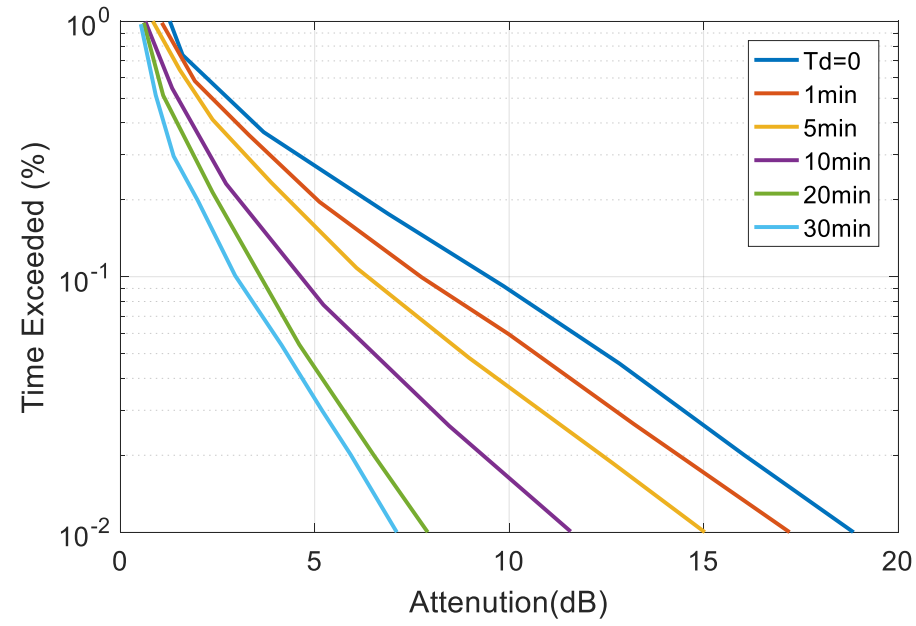

Figure 4. Joint CCDFs of Rain Attenuation for several time delays at Ku band 


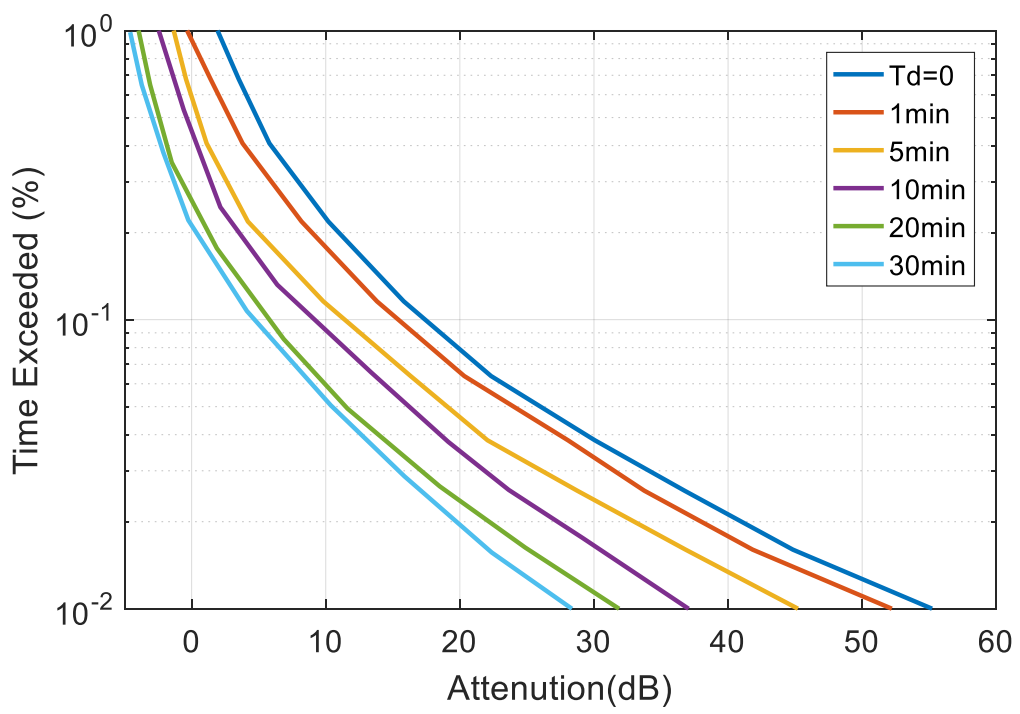

Figure 5. Joint CCDFs of Rain Attenuation for several time delays at Ka band

The performance of time diversity can also be quantified through the diversity gain. Figure 6 shows the diversity gain $G$ as a function of attenuation for several time delays that have been chosen. It is evident that for a given level of time exceeding percentage, the gain increases as the time delays and attenuation level increases. For instance, at frequency of $12 \mathrm{GHz}$ (Ku band) with attenuation level for $10 \mathrm{~dB}$, a gain of $4.3 \mathrm{~dB}$ is experienced for time delays $\Delta t=5$ minute which increased to 8 and $12 \mathrm{~dB}$ for time delays, $\Delta t=10$ and 30 minutes, respectively. Meanwhile, for frequency at $20 \mathrm{GHz}$ with the same level of attenuation the gain of $7 \mathrm{~dB}$ is experienced for time delays, $\Delta t=5$ minute that later increased to 8.5 and $16.5 \mathrm{~dB}$ for corresponding time delays, $\Delta t=10$ and 30 minutes. This is because high attenuation (corresponds to higher intensity of rain) tends to be in short duration which likely contribute to a better performance in mitigation process. However, as the time delay increase the relative gain curve is steeper and tends to saturate at higher attenuation. This indicate that time diversity reaches its efficiency limit and make it less effective for longer time delays.

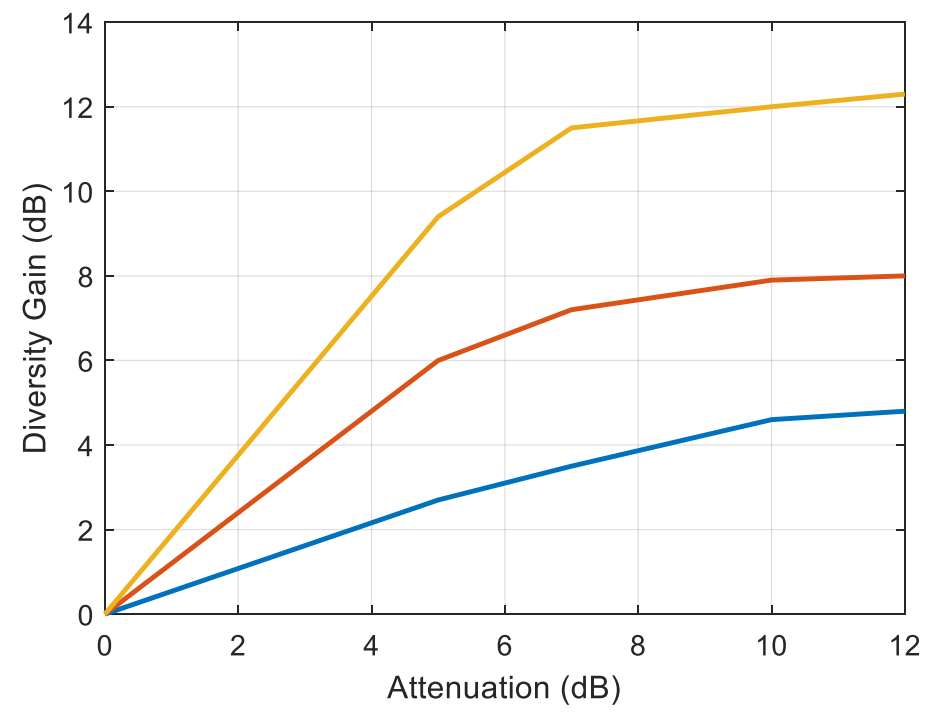

Figure 6. Diversity gain as a function of the rain attenuation for different time delay (Ku Band) 


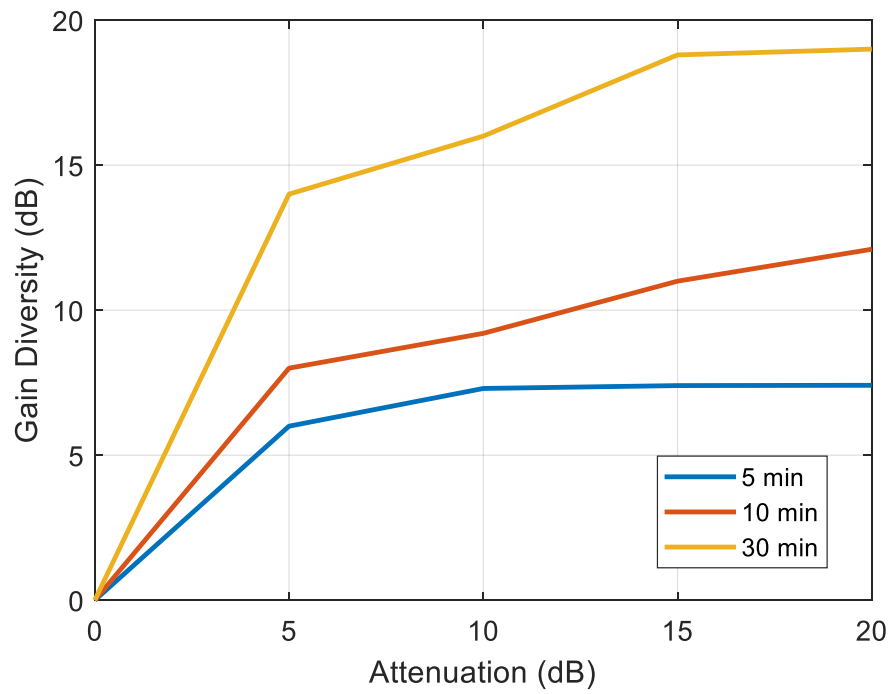

Figure 7. Diversity gain as a function of the rain attenuation for different time delay (Ka Band)

In addition, it is also found that huge discrepancy can be seen of its gain value for different level of frequencies. Comparison of gain experienced for two different frequencies at $\mathrm{Ku}$ and $\mathrm{Ka}$ band at 10 minutes' tolerance is showed in Table 3. The results show that Ka band experienced higher gain values due to stronger attenuation at higher frequency than that in lower frequency.

Table 3. Comparison of gain value for $\mathrm{Ku}$ and $\mathrm{Ka}$ band at 10 min time tolerance for $8 \mathrm{~dB}$ attenuation

\begin{tabular}{lcc}
\hline Frequency $(\mathbf{G H z})$ & $\begin{array}{c}\text { \%link } \\
\text { availability }\end{array}$ & $\begin{array}{c}\text { Diversity Gain } \\
(\mathbf{d B})\end{array}$ \\
\hline $\mathrm{Ku}(12 \mathrm{GHz})$ & & 6.2 \\
$\mathrm{Ka}(20 \mathrm{GHz})$ & $99.99 \%$ & 16.4 \\
\hline
\end{tabular}

For validation, SST predicted relative diversity gain (2) is compared to experimental time diversity analysis measured at Ku-band in Johor Bahru [11] together with the analytical model developed in [8] for 2 and $4 \mathrm{~dB}$ attenuation thresholds, as shown in Figure 8 (a) and (b). The predicted and measured relative diversity gain shows a close agreement particularly at $2 \mathrm{~dB}$, demonstrating the effectiveness of SST model in predicting time diversity performance in this region. On the other hand, the proposed model for time diversity application based on joint lognormal distribution in [8] seem to show underestimation at both attenuation thresholds. The deviation observed is mainly due to the failure of lognormal distribution to represent rain attenuation statistics in heavy rain region, as reported in [8] and [10]. In addition, relative diversity gain for Ka-band also provided in Figure 9 (a) at $2 \mathrm{~dB}$ and (b) at $4 \mathrm{~dB}$. Further study can be focuses on validation of time diversity performance at Ka-band and extend the simulation into longer duration of rain rate data.
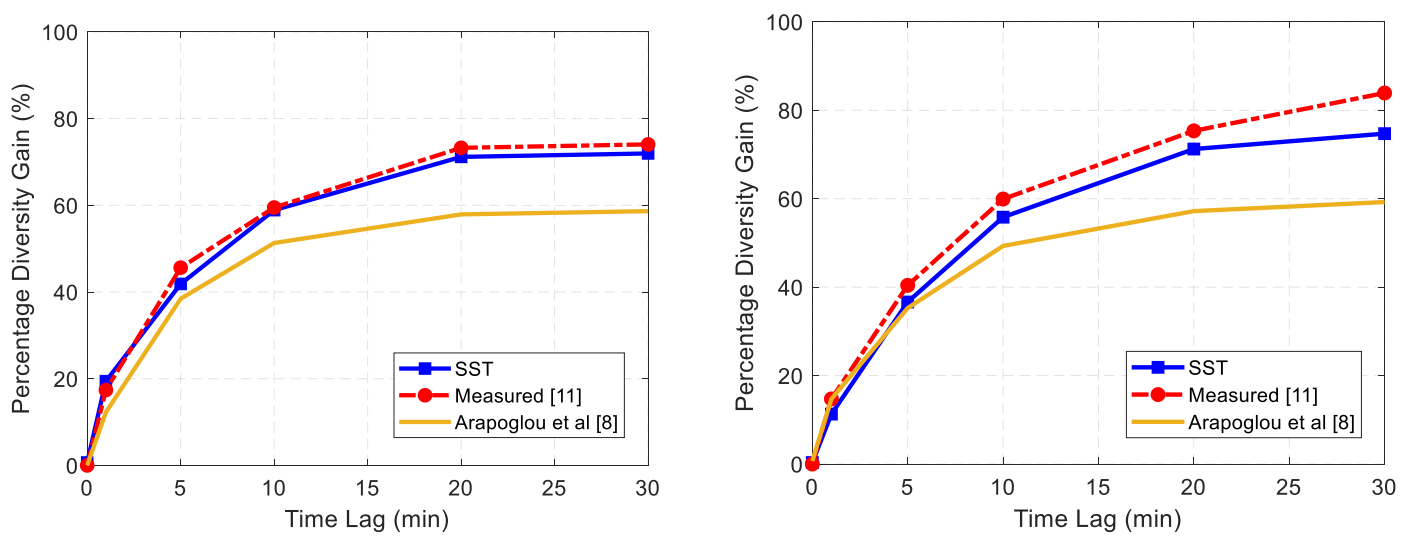

Figure 8. Comparison of relative diversity gain as a function of time lag at Ku-band for (a) $2 \mathrm{~dB}$ and (b) $4 \mathrm{~dB}$ attenuation thresholds between SST prediction, measurement, and analytical model [8]. 

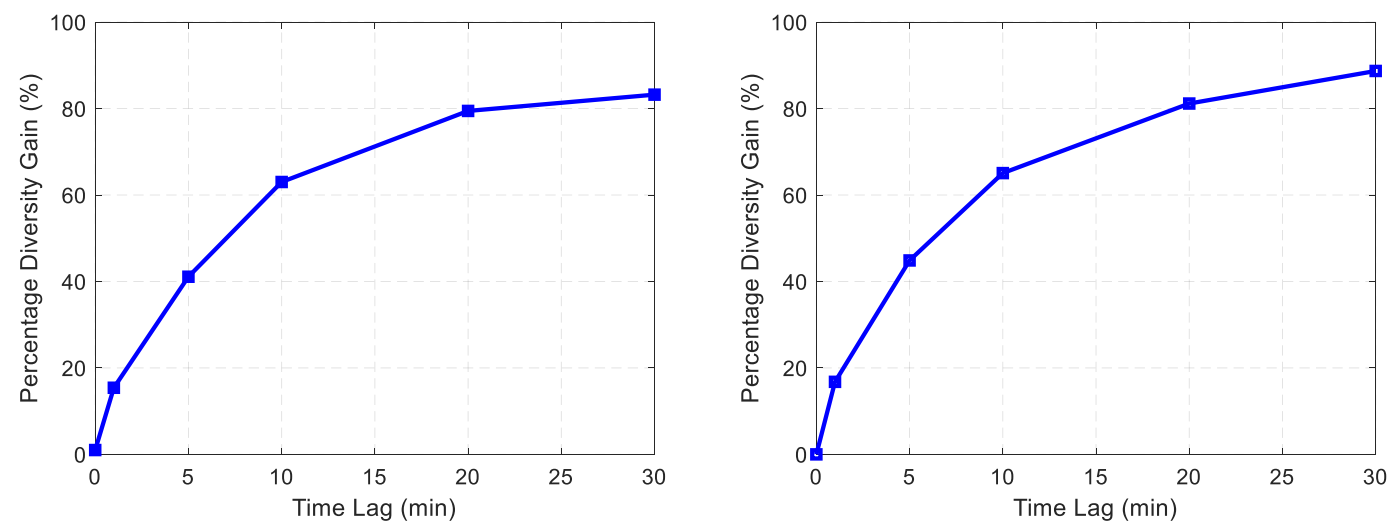

Figure 9. Relative diversity gain as a function of time lag at Ka-band for (a) $2 \mathrm{~dB}$ and (b) $4 \mathrm{~dB}$.

\section{CONCLUSION}

This study focuses primarily on a time diversity performance estimated for tropical climate of Johor Bahru, Malaysia and for different frequencies at $\mathrm{Ku}-(12 \mathrm{GHz})$ and $\mathrm{Ka}-\mathrm{Band}(20 \mathrm{GHz})$. The SST model is used utilizing the rain rate time series collected by the rain gauge for one-year duration. Analysis on time diversity technique appears to be short in duration with extremely high intensity. It was proven as an effective method to mitigate the deep fades if the time delay being chose carefully. Based on the obtained results, it depicts that gain value increasing as the time delay and attenuation level increases. Even though longer time delay resulted to higher gain, but saturation effect can be detected for further increasing the time delay. In other word, it means time diversity technique becomes inefficient and ineffective for prolong time delay. Hence, this will be beneficial for tropical region with intense rain at short duration.

\section{ACKNOWLEDGMENTS}

The authors are grateful for UTM, Skudai, Malaysia for providing the data and UTeM, Melaka, Malaysia for sponsoring the work.

\section{REFERENCES}

[1] Ippolito. L. J, Radiowave propagation in satellite communications, Springer Science \& Business Media, 2012.

[2] A. D. Panagopoulos, P.-D. M. Arapoglou, and P. G. Cottis, "Satellite communications at Ku, Ka, and V bands: propagation impairments and mitigation technique," IEEE Communications. Surveys \& Tutorials, vol. 6, no. 3, pp. 2$14,2004$.

[3] E. Matricciani, "Time diversity as a rain attenuation countermeasure in satellite links in the 10-100 GHz frequency bands," First European Conference on Antennas and Propagation, pp. 1-6, 2006.

[4] A. Kelmendi, A. Švigelj and A. Hrovat, "Statistical Analysis of Satellite Communication Experimental Time Diversity in Slovenia," 14th European Conference on Antennas and Propagation (EuCAP), pp. 1-5, 2020.

[5] P. Chodkaveekityada, and H. Fukuchi, "Time diversity evaluation for attenuation mitigation method using attenuation data in Thailand and Japan," International Journal of Satellite Communications and Networking, vol. 35.4, pp. 295$305,2017$.

[6] C. I. Kourogiorgas, et al., "On the outage probability prediction of time diversity scheme in broadband satellite communication systems," Progress in Electromagnetics Research, vol. 44, pp. 175-184, 2013.

[7] V. Fabbro, L. Castanet, S. Croce, and C. Riva, "Characterization and modelling of time diversity statistics for satellite communications from 12 to $50 \mathrm{GHz}$," International Journal of Satellite Communications and Networking, vol. 27, no.2, pp. 87-101, 2009.

[8] Pantelis-Daniel M. Arapoglou, Athanasios D. Panagopoulos, and Panayotis G. Cottis, "An analytical Prediction Model of Time Diversity Performance for Earth-Space Fade Mitigation," International Journal of Antennas and Propagation, 2008.

[9] L. Luini, A. Panzeri, C. Riva, D. Pimienta-del-Valle and J. M. Riera, "A Time Diversity Model for EHF Satellite Communication Systems," IEEE Transactions on Antennas and Propagation, 2021. 
[10] A. F. Ismail, P.A. Watson, "Characteristics of fading and fade countermeasures on a satellite-earth link operating in an equatorial climate with reference to broadcast applications," IEEE Proceedings Microw. Antennas Propag., vol. 147, no. 5, pp. 369-373, 2000.

[11] S. L. Jong, M. D'Amico, J. Din, and H. Y. Lam, "Performance of time diversity technique in heavy rain region," ISAP Int. Symp. Antennas Propagation, Conf. Proc., pp. 575-576, 2014.

[12] H. Y. Lam, L. Luini, J. Din, C. Capsoni, and A. D. Panagopoulos, "Performance of SatCom systems implementing time diversity in equatorial Malaysia," 8th European Conference on Antennas and Propagation (EuCAP), pp. 511514, 2014.

[13] Alam, Md. Moktarul et al, "Investigation of time diversity gain for earth to satellite link using rain rate gain," Bulletin of Electrical Engineering and Informatics, vol. 8, no. 3, pp. 951-959, 2019.

[14] M. M Yunus, J Din, H. Y Lam, and S. L Jong, "Estimation of Interfade Duration for Ku- and Ka-Band Satellite Communication System in Equatorial Malaysia," URSI Asia Pacific Radio Science Conference, Korea. Pp. 19671970, 2016.

[15] E. Matricciani, "Physical-mathematical model of the dynamics of rain attenuation based on rain rate time series and a two-layer vertical structure of precipitation," Radio Sci., vol.31, no.2 pp. 281-295, 1996.

[16] Jong, S. L., Riva, C., D’Amico, M., Lam, H. Y., Yunus, M. M., \& Din, J., "Performance of synthetic storm technique in estimating fade dynamics in equatorial Malaysia," International Journal of Satellite Communications and Networking, vol. 36, no.5, pp. 416-426, 2018.

[17] ITU-R P.618-13, "Propagation data and prediction methods required for the design of earth-space telecommunication systems," 2017.

[18] ITU-R P.838-3, "Specific attenuation model for rain for use in prediction methods", 2005.

[19] ITU-R P.839-4, "Rain Height Model for Prediction Methods," 2013. 